\title{
STRATEGI PENGELOLAAN DANA ZAKAT TERHADAP PROGRAM SANTUNAN KESEHATAN MASYARAKAT
}

\author{
M Fajran Sidiq P, Andi Intan Cahyani \\ Universitas Islam Negeri Alauddin Makassar \\ Email:fajransidik27@gmail.com
}

\begin{abstract}
Abstrak
Zakat merupakan salah satu rukun Islam yang ketiga. Zakat mempunyai kedudukan dan posisi yang penting karena keberadaannya menyangkut aspek kehidupan masyarakat. Salah satunya bagi umat muslim yang membutuhkan dana untuk kesehatan BAZNAS Kota Makassar selaku lembaga pengelola zakat, memiliki legalitas untuk membuat program dalam pendayagunaan dana zakat terkhusus menjalankan salah satu programnya yakni Makassar Sehat yaitu memberikan bantuan kepada Mustahik terkait dengan penjaminan kesehatan. Banyak masyarakat khususnya masyarakat Kota Makassar yang berekonomi lemah kurang mendapatkan bantuan dan pelayanan kesehatan yang baik. Pokok permasalahan pada penelitian ini adalah strategi dari pengelolaan dana zakat terhadap program santunan kesehatan masyarakat yang dilakukan oleh Badan Amil Zakat Nasional (BAZNAS) Kota Makassar. Jenis penelitian ini adalah penelitian lapangan (field research) menggunakan metode kualitatif dengan pendekatan penelitian yang digunakan adalah yuridis dan empiris dan syariat. Berdasarkan hasil penelitian ini menunjukkan bahwa strategi Badan Amil Zakat Nasional (BAZNAS) Kota Makassar terhadap pengelolaan dana zakat untuk program bantuan kesehatan atau Makassar sehat, BAZNAS Kota Makassar terlebih dahulu membuat Rencana kerja dan Anggaran tahunan (RKAT) yang dilakukan di akhir tahun tepatnya bulan desember dengan melihat hasil evaluasi kegiatan di tahun sebelumnya serta membuat target penyaluran yang disesuaikan dengan program-program yang telah ditetapkan oleh BAZNAS Kota Makassar.
\end{abstract}

Kata Kunci : Baznas, Hukum Islam, Kesehatan Masyarakat, Pengelolaan Zakat

\begin{abstract}
Zakat is one of the third pillars of Islam. Zakat has an important position and position because its existence involves aspects of people's lives. One of them is for Muslims who need funds for health BAZNAS Makassar City as a zakat management institution, has the legality to create programs in the utilization of zakat funds, especially running one of its programs, namely Healthy Makassar, which is to provide assistance to Mustahik related to health insurance. Many people, especially the people of Makassar City, who are economically weak, do not get good health assistance and services. The main problem in this study is the strategy of managing zakat funds for the public health compensation program carried out by the National Amil Zakat Agency (BAZNAS) Makassar City. This type of research is field research using qualitative methods with the research approach used is juridical and empirical and sharia. Based on the results of this study indicate that the Makassar City National Amil Zakat Agency (BAZNAS) strategy towards the management of zakat funds for health assistance programs or healthy Makassar, Makassar City BAZNAS first makes an annual work plan and budget (RKAT) which is carried out at the end of the year to be exact in December by looking at the results of the
\end{abstract}


evaluation of activities in the previous year and making distribution targets that are adjusted to the programs that have been set by the Makassar City BAZNAS.

Keywords: Baznas, Islamic Law, Public Health, Zakat Management

\section{A. PENDAHULUAN}

Zakat merupakan rukun Islam yang ketiga sesudah shalat yang menjadikan perintah menunaikan zakat merupakan kewajiban bagi setiap muslim, sama halnya perintah menunaikan shalat. Ketika zakat dapat ditunaikan dengan baik maka dapat mendatangkan kemanfaatan bagi diri sendiri terutama dalam membersihkan jiwa dan meningkatkan kualitas keimanan serta memberikan keberkahan terhadap harta dan juga mendatangkan kemanfaatan bagi yang berhak menerimanya dalam keberlangsungan kehidupan Allah swt. berfirman dalam QS. alTaubah/9:103

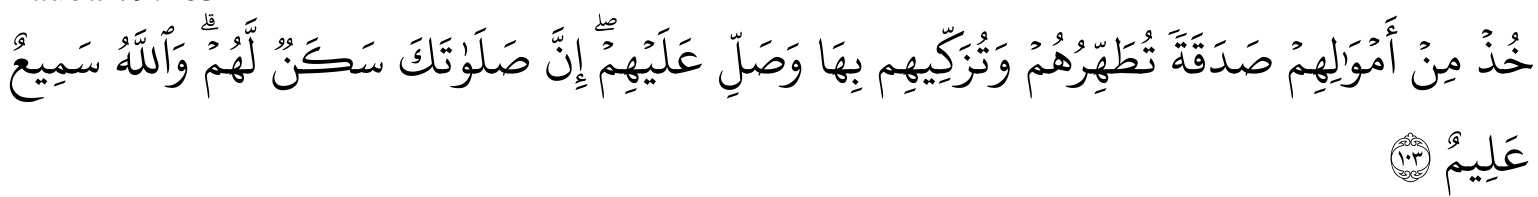

Terjemahnya:

"Ambillah zakat dari harta mereka, guna membersihkan dan mensucikan mereka dan berdoalah untuk mereka. Sesungguhnya doamu itu (menumbuhkan) ketentraman jiwa bagi mereka. Dan Allah maha mendengar lagi maha mengetahui". ${ }^{1}$

Berdasarkan ayat tersebut, zakat wajib dikeluarkan dari yang berkewajiban untuk berzakat (muzakki) untuk kemudian diberikan kepada yang berhak menerimanya (mustahik).Bahkan pada zaman khalifah Abu bakar al-Shiddiq, orang yang telah memenuhi persyaratan untuk mengeluarkan zakat dan enggan untuk berzakat dinyatakan telah murtad.

Peran zakat dalam menanggulangi kemiskinan merupakan suatu hal yang penting yang tidak bisa dipungkiri keberadaannya. Dalam pandangan masyarakat umum, pengetahuan tentang tujuan dari zakat itu sendiri hanyalah menanggulangi kemiskinan dan membantu kebutuhan para fakir miskin tanpa mengetahui gambarannya secara gamblang dan utuh. Kebijakan tersebut telah tertuang dalam Undang-Undang Nomor 23 Tahun 2011 Tentang Pengelolaan Zakat. Dalam undang-undang tersebut dijelaskan bahwa pengelolaan zakat bertujuan untuk meningkatkan efektivitas dan efisiensi pelayanan dalam pengelolaan zakat dan meningkatkan manfaat zakat untuk mewujudkan kesejahteraan masyarakat dan penanggulangan kemiskinan. Oleh sebab itu dibutuhkan suatu lembaga yang mengatur itu semua. Dalam Undang-undang Republik Indonesia nomor 23 tahun 2011 tentang pengelolaan dana zakat telah dijelaskan bahwa pemerintah wajib membentuk Badan Amil Zakat Nasional (BAZNAS) yang memiliki fungsi sebagai perencana, pelaksana dan pengendalian terhadap pengumpulan, pendistribusian dan pendayagunaan zakat serta mempertanggungjawabkan pelaksanaan pengelolaan zakat itu sendiri.

Selaku lembaga pengelola zakat, BAZNAS Kota Makassar memiliki legalitas untuk membuat program dalam pendayagunaan dana zakat terkhusus menjalankan salah satu programnya yakni Makassar Sehat yaitu memberikan bantuan kepada Mustahik terkait dengan penjaminan kesehatan. Karena memperoleh bantuan dan layanan kesehatan yang baik adalah hak semua orang tidak terkecuali untuk masyarakat kurang mampu.Banyak masyarakat khususnya masyarakat Kota Makassar yang berekonomi lemah kurang mendapatkan bantuan dan pelayanan kesehatan yang baik.

${ }^{1}$ Kementerian Agama RI, al-Qur'an dan Terjemahnya, (Solo: PT. Maghfirah Pustaka, 2012), h. 203. 


\section{B. METODOLOGI PENELITIAN}

Penelitian ini adalah penelitian lapangan (field research) menggunakan metode kualitatif dengan pendekatan penelitian yang digunakan adalah pendekatan syar'i, yuridis dan empiris. Adapun sumber data penelitian ini adalah sumber data primer yaitu wawancara langsung kepada narasumber yang terkait dengan penelitian ini. Kedua, sumber data sekunder yang bersumber dari dalam bentuk dokumen, buku, jurnal penelitian. Metode pengumpulan data dilakukan adalah observasi, wawancara, dan dokumentasi, kemudian teknik pengelolaan dan analisis data dilakukan melalui beberapa tahap yaitu reduksi data, penyajian data dan penarikan kesimpulan.

\section{HASIL PEMBAHASAN}

1. Sistem Pengelolaan Zakat oleh BAZNAS Kota Makassar Terhadap Program Santunan Kesehatan Masyarakat

Berdasarkan Undang-Undang No. 23 tahun 2011 pasal 2 ayat 1 pemerintah membentuk BAZNAS untuk melaksanakan pengelolaan zakat secara nasional. ${ }^{2}$ Berdasarkan keputusan tersebut maka pengelolaan zakat sepenuhnya dilakukan oleh BAZNAS dan dibantu unit pengumpulan zakat (UPZ) yang dibentuk oleh BAZNAS untuk membantu pengumpulan zakat. Pengelolaan zakat di BAZNAS Kota Makassar memiliki beberapa tahap yang harus dilakukan. Hal ini mengikuti ketentuan dari BAZNAS pusat yang mana tahap-tahapnya terdiri dari perencanaan, pengumpulan, pendistribusian dan evaluasi.

BAZNAS Kota Makassar telah membuat Rancangan Keuangan Anggaran Tahunan untuk tahun 2021 ini, dimana target penyaluran untuk tahun ini sebesar Rp. 29.230.318.500 (Dua puluh sembilan miliar dua ratus tiga puluh juta tiga ratus delapan belas ribu lima ratus rupiah) untuk semua program yang telah ditetapkan. Adapun perencanaan target penyaluran bidang kesehatan atau program Makassar Sehat itu sendiri sebesar Rp. 894.000.000 ( Delapan ratus sembilan puluh empat juta rupiah) yang bersumber dari dana zakat sebesar 3,2\% dan dana infaq/sedekah sebesar 18,7 \% dengan perincian sebagai berikut:

\begin{tabular}{|c|c|c|c|c|c|c|}
\hline $\begin{array}{c}\text { Bentuk } \\
\text { Kegiatan }\end{array}$ & Sasaran & Tujuan & $\begin{array}{c}\text { Kebutuhan } \\
\text { Yang Di } \\
\text { Salurkan }\end{array}$ & Jumlah & $\begin{array}{l}\text { Harga } \\
\text { Satuan }\end{array}$ & Jumlah \\
\hline \multicolumn{6}{|c|}{ 1. Pengobatan Massal } & Rp.450.000.000 \\
\hline & \multirow{4}{*}{$\begin{array}{c}\text { Masyaraka } \\
\text { t miskin } \\
\text { pada } \\
\text { wilayah } \\
\text { kumuh }\end{array}$} & \multirow{4}{*}{$\begin{array}{l}\text { Kesehatan } \\
\text { masyarakat } \\
\text { meningkat }\end{array}$} & Paket sembako & 300 paket & Rp.125.000 & Rp.375.000.000 \\
\hline & & & Dokter & 4 org & Rp.500.000 & Rp.30.000.000 \\
\hline & & & Paramedis & 6 org & Rp.200.000 & Rp.18.000.000 \\
\hline & & & Pengurus & 12 org & Rp.150.000 & Rp.27.000.000 \\
\hline \multicolumn{6}{|c|}{ 2. Sunatan Massal } & Rp.114.000.000 \\
\hline & \multirow{4}{*}{$\begin{array}{c}\text { Anak Fakir } \\
\text { Miskin }\end{array}$} & \multirow{4}{*}{$\begin{array}{c}\text { Kesehatan } \\
\text { Anak } \\
\text { Meningkat }\end{array}$} & $\begin{array}{l}\text { Paket } \\
\text { Perlengkapan }\end{array}$ & $150 \times 2$ & Rp.50.000 & Rp.15.000.000 \\
\hline & & & Dokter & $6 \times 2$ & Rp.500.000 & Rp.6.000.000 \\
\hline & & & Paramedis & $35 \times 2$ & Rp.300.000 & Rp.21.000.000 \\
\hline & & & Konsumsi & $400 \times 2$ & Rp.50.000 & Rp.40.000.000 \\
\hline
\end{tabular}

${ }^{2}$ Republik Indonesia, “Undang-Undang RI Nomor 23 Tahun 2011 tentang Pengelolaan Zakat” dalam Kementerian Agama RI, Panduan Zakat Praktis, (Jakarta: Kementerian Agama RI, 2013), h. 100. 


\begin{tabular}{|c|c|c|c|c|c|c|}
\hline & & & Pengurus & $32 \times 2$ & Rp.500.000 & Rp.32.000.000 \\
\hline $\begin{array}{l}\text { 3. Pengadaan } \\
\text { obat-obatan }\end{array}$ & $\begin{array}{c}\text { Masyarakat } \\
\text { miskin }\end{array}$ & $\begin{array}{l}\text { Tersedianya } \\
\text { obat }\end{array}$ & LS & LS & $\mathrm{LS}$ & Rp.50.000.000 \\
\hline 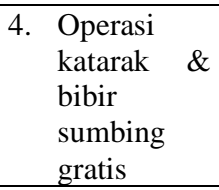 & $\begin{array}{l}\text { Pasien } \\
\text { miskin }\end{array}$ & $\begin{array}{c}\text { Meningkatny } \\
\text { a kesehatan } \\
\text { masyarakat }\end{array}$ & Mata dan bibir & 10 & Rp.3.000.000 & Rp.30.000.000 \\
\hline $\begin{array}{l}\text { 5. Bantuan } \\
\text { biaya RS } \\
\text { bagi Fakir } \\
\text { miskin } \\
\text { terseleksi }\end{array}$ & $\begin{array}{l}\text { Pasien } \\
\text { Miskin }\end{array}$ & $\begin{array}{l}\text { Meningkatny } \\
\text { a kesehatan } \\
\text { masyarakat }\end{array}$ & $\begin{array}{l}\text { BPJS, dana } \\
\text { kesehatan \& } \\
\text { RSB }\end{array}$ & LS & LS & Rp.250.000.000 \\
\hline \multicolumn{6}{|c|}{ Total Anggaran Makassar Sehat } & Rp.894.000.000 \\
\hline
\end{tabular}

Berdasarkan laporan pengumpulan dana oleh BAZNAS Kota Makassar pada tahun 2020 jumlah dana yang terkumpul dari dana zakat, infaq, sedekah dan dana sosial keagamaan sebesar Rp. 23.022.359.701 dari dana-dana yang terkumpul inilah yang kemudian akan didistribusikan ke program-program kegiatan yang telah ditetapkan oleh BAZNAS baik secara konsumtif maupun produktif.

Laporan pengumpulan dana oleh BAZNAS Kota Makassar tahun 2020:

Table 1. Pengumpulan dana Zakat

\begin{tabular}{|c|l|l|}
\hline NO & \multicolumn{1}{|c|}{ URAIAN } & \multicolumn{1}{c|}{ JUMLAH } \\
\hline & \multicolumn{1}{|c|}{ Pengumpulan/penerimaan zakat } & \\
\hline 1 & Penerimaan zakat perorangan & Rp. 360.068 .719 \\
\hline 2 & Penerimaan zakat Badan/UPZ & Rp. 1.994 .774 .053 \\
\hline 3 & Penerimaan zakat pertanian & Rp. 1.000 .000 \\
\hline 4 & Penerimaan zakat Fitrah & Rp. 3.568.984.000 \\
\hline & TOTAL & Rp. 5.924.826.772 \\
\hline
\end{tabular}

Tabel 2. Pengumpulan Dana Infaq/Sedekah

\begin{tabular}{|c|l|l|}
\hline NO & \multicolumn{1}{|c|}{ Pengumpulan dana infak/sedekah } & \multicolumn{1}{c|}{ JUMLAH } \\
\hline 1 & Infaq Perorangan & Rp. 19.883 .690 \\
\hline 2 & Infaq Badan/UPZ & Rp. 951.588 .759 \\
\hline 3 & Infaq kupon \& kotak amal & Rp. 39.608.250 \\
\hline 4 & Infaq Haji TOTAL & Rp. 955.000 .000 \\
\hline & \multicolumn{2}{|c|}{ TOC.968.699 } \\
\hline
\end{tabular}

Tabel 3. Pengumpulan DSKL

\begin{tabular}{|c|l|l|}
\hline NO & \multicolumn{1}{|c|}{ Penerimaan DKSL } & \multicolumn{1}{|c|}{ JUMLAH } \\
\hline 1 & Hibah APBD & Rp. 2.000 .000 .000 \\
\hline 2 & Penerimaan Qurban & Rp. 13.106 .750 .000 \\
\hline 3 & Penerimaan Fidyah & Rp. 4.230.000 \\
\hline 4 & Penerimaan Dana Sumbangan & - \\
\hline 5 & CSR dan bagi hasil (Jasa Giro) & Rp. 20.472.230 \\
\hline & TOTAL & Rp. 15.131.452.230 \\
\hline
\end{tabular}

Pelaksanaan program ataupun kegiatan tentunya memiliki kekurangan dan kelebihan. Evaluasi untuk melihat kembali apa yang perlu diperbaiki dan ditingkatkan setelah program tersebut telah dilakukan. Dalam proses evaluasi BAZNAS Kota makassar membagi menjadi beberapa evaluasi dan tentunya tetap melihat aturan dari BAZNAS 
Pusat yakni evaluasi bagian, evaluasi per enam bulan dan juga satu tahun. Evaluasi ditunjang dengan diadakannya rapat pegawai.

Evaluasi yang dilakukan oleh BAZNAS Kota Makassar tentunya sangat berpengaruh terhadap perencanaan pengelolaan dana zakat untuk tahun selanjutnya. Karena dalam menyusun perencanaan tentunya melihat dari hasil evaluasi di tahun sebelumnya agar adanya perbaikan maupun peningkatan yang akan dilakukan oleh BAZNAS Kota Makassar.

\section{Perspektif Hukum Islam Terhadap Pengelolaan Dana Zakat Oleh BAZNAS Kota Makassar Untuk Program Bantuan Kesehatan Masyarakat}

Berdasarkan nash al-Qur'an penyaluran dana zakat untuk bantuan kesehatan masyarakat memang tidak disebutkan secara tegas akan tetapi ada celah bagi para ulama memperbolehkan dana zakat untuk bantuan kesehatan masyarakat.

Menurut Imam syar'i cara pandang lama terhadap pengelolaan zakat belum juga mengalami perubahan secara drastis dan signifikan meskipun pemikiran-pemikiran baru berkenaan dengan zakat telah diperkenalkan, akibatnya pola berzakat masyarakat masih bersifat tradisional. Berbeda dengan pendapat ulama kontemporer yaitu Yusuf Qardhawi, melihat potensi zakat yang bisa digali dari umat islam, maka ada beberapa aspek dari zakat yang harus segera diperbaharui salah satunya adanya aspek pendayagunaan yang berarti menyangkut aspek pemanfaatan zakat. ${ }^{3}$

Wahbah al-Zuhaily memandang makna al-Shadaqat dalam al-Qur'an surah at-Taubah: 60 mengandung makna umum, mencakup zakat wajib dan sunnah. Dalam ayat tersebut yang dimaksud dengan makna wajib yang terkandung dalam lafadz "faridha". Secara tekstual ayat tersebut mengindikasikan penggunaan lafadz "innama" mengandung makna hasr yang berarti zakat merupakan hak mustahik. Zakat secara kontekstual MUI menggunakan ayat tersebut untuk mendudukan terma harta yang dimiliki muzakki terhadap harta mustahik zakat yang wajib diberikan. ${ }^{4}$

Pada penjelasan Imam al-Qurthubi dalam kitabnya al-Jami' li Ahkam al-Qur'an "bahwasannya amil zakat adalah petugas yang diangkat oleh pemerintah untuk mengambil dan mengumpulkan zakat seizing dari imam tersebut". ${ }^{5}$ Bahwa manajemen BAZNAS Kota Makassar ditunjuk oleh pemerintah dalam hal ini oleh BAZNAS Pusat untuk menjalankan operasionalnya.

Syaikh Muhammad bin Shalih dalam bukunya Ensiklopedia zakat dan fatwa zakat Utsaimin mengatakan "Amil zakat adalah orang-orang yang diangkat oleh pengusaha untuk mengambil zakat dari orang-orang yang berkewajiban untuk menunaikannya lalu menjaga dan mendistribusikan untuk asnaf yang telah ditentukan oleh nash al-Qur'an. ${ }^{6}$ BAZNAS Kota Makassar sendiri telah menyusun bidang-bidang yang terdiri dari pegawai BAZNAS dalam pengelolaan dana zakat, infak dan sedekah sesuai dengan fatwa tersebut. Oleh karena tanggung jawab BAZNAS Kota Makassar untuk menyalurkan zakat untuk

\footnotetext{
${ }^{3}$ Syukri Ghozali, dkk, Pedoman Zakat 9 Seri (Jakarta: Proyek Peningkatan Sarana Keagamaan Islam, Zakat dan Wakaf, 2001), h.84.

${ }^{4}$ Wahbah az-Zuhaili, Fiqhul Islam wa Adillatuhu, Terj. Abdul Hayyi, Fikih Islam dan Dali-dalil nya (Jakarta:Gema Insani,2010), h. 115.

5Imam al-Qurthubi, Al Jami' Li Ahkam al-Qur'an, Terj. Budi Rosyadi dkk, Tafsir al-Qurthubi Jilid 8 (Jakarta: Pustaka Azzam,2007), h.

${ }^{6}$ Muhammad bin Shalih Al-Utsaimin, Fatawa fii Ahkami Az-Zakat, Terj. Sri Mulyati dkk.Ensiklopedi Zakat, Kumpulan Fatwa Zakat (Jakarta: Pustaka as-Sunnah, 2008), h.67.
} 
kebutuhan fakir miskin baik yang bersifat konsumtif maupun produktif. Bantuan kesehatan sendiri masuk dalam kebutuhan konsumtif para mustahik.

Berdasarkan penjelasan beberapa pendapat-pendapat ulama, fatwa serta perundangundangan yang ada serta hasil wawancara yang kami lakukan di BAZNAS Kota Makassar terkait perspektif Hukum Islam tentang bantuan kesehatan masyarakat Kota Makassar tentunya memiliki keterkaitan satu sama lain. Dimana dalam memberikan bantuan kesehatan kepada mustahik melalui dana zakat, BAZNAS Kota Makassar mengkategorikan bantuan kesehatan tersebut untuk diberikan ke 8 asnaf yang berhak menerimanya atau lebih tepatnya bantuan kesehatan itu ditujukan untuk kaum fakir miskin yang membutuhkan bantuan kesehatan, karena bantuan kesehatan merupakan bantuan konsumtif serta menjadi hal yang harus diperoleh kaum fakir miskin. Sebagaimana program yang telah ditetapkan oleh BAZNAS Kota Makassar tentang sosial kesehatan diantaranya pengobatan massal yang ditujukan untuk masyarakat miskin, Sunatan massal untuk anak fakir miskin, pengadaan obat-obatan untuk masyarakat miskin hingga bantuan biaya rumah sakit bagi fakir miskin terseleksi.

\section{KESIMPULAN}

Berdasarkan pembahasan diatas, penulis mengambil kesimpulan sebagai berikut :

1. Strategi Badan Amil Zakat Nasional (BAZNAS) Kota Makassar terhadap pengelolaan dana zakat untuk program bantuan kesehatan atau Makassar sehat, BAZNAS Kota Makassar terlebih dahulu membuat Rencana kerja dan Anggaran tahunan (RKAT) yang dilakukan di akhir tahun tepatnya bulan desember dengan melihat hasil evaluasi kegiatan di tahun sebelumnya serta membuat target penyaluran yang disesuaikan dengan program-program yang telah ditetapkan oleh BAZNAS Kota Makassar. Kemudian dalam pengumpulan dana zakat, infaq, sedekah dan dana sosial keagamaan lainnya, BAZNAS Kota Makassar membuat Unit Pengumpulan Zakat (UPZ) di beberapa lokasi di Kota Makassar untuk mempermudah muzakki dalam berzakat. Kemudian dari hasil pengumpulan dana tersebut BAZNAS melakukan pendistribusian berdasarkan program yang telah disusun dengan memperhatikan 8 asnaf yang berhak dizakati. Pendistribusian untuk program bantuan kesehatan sendiri itu bersumber dari dana zakat dan infak/sedekah yang telah dialokasikan untuk beberapa bantuan kesehatan diantaranya pengobatan massal untuk masyarakat miskin, sunatan massal untuk anak fakir miskin, pengadaan obat-obatan untuk fakir miskin, operasi katarak dan bibir sumbing gratis untuk pasien miskin serta bantuan biaya rumah sakit bagi fakir miskin terseleksi. BAZNAS Kota Makassar juga melakukan evaluasi yang terdiri dari evaluasi per bidang, evaluasi per enam bulan serta evaluasi yang dilakukan sekali dalam setahun. Untuk evaluasi per enam bulan BAZNAS Kota Makassar membuat laporan kerja selama enam bulan ke BAZNAS Pusat dan diikuti oleh laporan akhir yakni laporan yang dilakukan sekali dalam setahun yakni rekapitulasi dari laporan per enam bulan ke BAZNAS pusat.

2. Dalam perspektif Hukum islam terkait dana zakat yang didistribusikan untuk program bantuan kesehatan masyarakat memang tidak dijelaskan secara rinci dan tekstual di dalam al-Qur'an, namun berdasarkan pendapat ulama serta fatwa-fatwa MUI terkait penyaluran dana zakat tetap mengharuskan agar 8 asnaf itu memperoleh bantuan dari dana zakat. Oleh karenanya BAZNAS Kota Makassar dalam menyalurkan bantuan kesehatan itu lebih tertuju untuk bantuan serta pelayanan kesehatan bagi fakir miskin. 
Oleh karena itu bantuan kesehatan masyarakat untuk fakir miskin telah sesuai dengan ketentuan syariat Islam. 


\section{Daftar Pustaka}

\section{Buku}

Ghozali, Syukri dkk, Pedoman Zakat 9 Seri, Jakarta: Proyek Peningkatan Sarana Keagamaan Islam, Zakat dan Wakaf, 2001.

Imam al-Qurthubi, Al Jami' Li Ahkam al-Qur'an, Terj. Budi Rosyadi dkk, Tafsir al-

Qurthubi Jilid 8, Jakarta: Pustaka Azzam,2007

Kementerian Agama RI, al-Qur'an dan Terjemahnya.,Solo: PT Maghfirah Pustaka, 2012.

Muhammad bin Shalih Al-Utsaimin, Fatawa fii Ahkami Az-Zakat, Terj. Sri Mulyati dkk.

Ensiklopedia Zakat, Kumpulan Fatwa Zakat (Jakarta: Pustaka as-Sunnah, 2008. az-Zuhaili, Wahbah, Fiqhul Islam wa Adillatuhu, Terj. Abdul Hayyi, Fikih Islam dan

Dali-dalil nya, Jakarta:Gema Insani,2010.

\section{Peraturan Perundang-undangan}

Republik Indonesia, "Undang-Undang RI Nomor 23 Tahun 2011 tentang Pengelolaan Zakat" dalam Kementrian Agama RI, Panduan Zakat Praktis, (Jakarta: Kementerian Agama RI, 2013 